\title{
Are food patterns associated with prostate cancer in Jamaican men:
} a preliminary report

\author{
Maria Jackson*1, Susan Walker ${ }^{2}$, Candace Simpson², Norma McFarlane- \\ Anderson $^{3}$ and Franklyn Bennett ${ }^{4}$
}

\begin{abstract}
Address: ${ }^{1}$ Dept. of Community Health and Psychiatry, University of the West Indies, Mona, Kingston, Jamaica, ${ }^{2}$ Tropical Medicine Research Institute, University of the West Indies, Mona, Kingston, Jamaica, ${ }^{3}$ Dept. of Basic Medical Sciences, University of the West Indies, Mona, Kingston, Jamaica and ${ }^{4}$ Dept. of Pathology, University of the West Indies, Mona, Kingston, Jamaica

Email: Maria Jackson* - maria.jackson@uwimona.edu.jm ; Susan Walker - susan.walker@uwimona.edu.jm;

Candace Simpson - candhimarhi@yahoo.com; Norma McFarlane-Anderson - norma.mcfarlaneanderson@uwimona.edu.jm;

Franklyn Bennett - franklyn.bennett@uwimona.edu.jm

* Corresponding author
\end{abstract}

from Second Annual International African-Caribbean Cancer Consortium Conference

Miami, FL, USA. 12-13 May 2008

Published: 10 February 2009

Infectious Agents and Cancer 2009, 4(Suppl I):S5 doi:I0.II86/I750-9378-4-SI-S5

This article is available from: http://www.infectagentscancer.com/content/4/SI/S5

(c) 2009 Jackson et al; licensee BioMed Central Ltd.

This is an open access article distributed under the terms of the Creative Commons Attribution License (http://creativecommons.org/licenses/by/2.0),

which permits unrestricted use, distribution, and reproduction in any medium, provided the original work is properly cited.

\begin{abstract}
Background: Morbidity and mortality data highlight prostate cancer as the most commonly diagnosed neoplasm in Jamaican males. This report examines the association between dietary patterns and risk of prostate cancer in Jamaican men.
\end{abstract}

Materials and methods: Case-control study of 204 histologically confirmed newly diagnosed prostate cancer cases and 204 individually matched urology clinic controls in Jamaica, 2004 - 2007. Diet was assessed by food frequency questionnaire.

Results: Factor analysis yielded four dietary patterns: (i) a "healthy" pattern of vegetables, fruits and peas and beans, (ii) a "carbohydrate" pattern with high loadings for white bread and refined cereals, (iii) "sugary foods and sweet baked products" pattern and (iv) a "organ meat and fast food pattern" with high loadings for high fat dessert, organ meat, fast food and salty snacks.

Logistic regressions with the individual dietary patterns controlling for potential confounders showed no association between any of the food patterns and risk of prostate cancer. The healthy pattern showed an inverse non-significant association, whereas the carbohydrate pattern was positively and insignificantly related to prostate cancer. Analysis of all food patterns adjusting for each other revealed no association between food patterns and the risk of prostate cancer.

Conclusion: Dietary patterns identified in our sample were not associated with risk of prostate cancer. Further investigations that better define cancer-free subjects and dietary measurements are needed to examine diet and prostate cancer outcomes. 


\section{Introduction}

Prostate cancer is the leading cancer site among Jamaican males $(30.3 \%)$ and the leading cause of cancer mortality (16.5\% of total cancer deaths) [1]. A review of age-specific incidence of cancer 1993 - 1997, revealed that age-standardized rate of prostate cancer increased from 36.0/ 100,000 to $56.4 / 100,000$ [2].

Diet may play a role in the development of prostate cancer. However, studies have been inconsistent in the dietary constituents that affect risk [3]. Another approach has been to examine association between patterns of food consumption and disease risk. In this study factor analysis was used to investigate the association of dietary patterns and prostate cancer in Jamaican men in a matched casecontrol study.

\section{Methods \\ Sample}

The study sample included consecutive men attending urology clinics at 2 major hospitals and private practitioners in Kingston Metropolitan area in Jamaica, 2005 2007. This investigation includes 204 histologically confirmed newly diagnosed prostate cancer cases and 204 age-matched urology clinic controls. Thirty-eight cases were excluded from analyses due to the unavailability of a matched control. The study was approved by the Ethics committee of the University of the West Indies and subjects gave written informed consent to participate in the study.

\section{Data collection}

\section{Dietary assessment}

Dietary intakes were assessed using a food frequency questionnaire developed to assess habitual diets of Jamaican adults. The FFQ was validated against twelve 24-hour recalls over 1 year and showed good agreement. For each food item, subjects provided information on portion size. The FFQ was interviewer-administered.

\section{Anthropometry}

Body weight (without shoes) was measured in clothing to the nearest $0.1 \mathrm{~kg}$. Height was measured without shoes on a floor standing stadiometer fitted with spirit level, to the nearest 0.1 centimetres. Body mass index was calculated and the World Health Organization's classification was used to determine overweight (BMI $>25.00 \mathrm{~kg} / \mathrm{m}^{2}$ ) and obesity (BMI $\geq 30.00 \mathrm{~kg} / \mathrm{m}^{2}$ ).

\section{Other information}

Information on demographic and socioeconomic factors, medical history, first-degree family history of prostate cancer and lifestyle were obtained by questionnaire.

\section{Identification of food patterns}

Patterns of food intake were identified by principal component with varimax (orthogonal) rotation to identify non-correlated factors [4]. Individual foods from the FFQ were aggregated into 33 groups, largely based on the macronutrient content of the food and culinary use. Daily intake of the food in grams from each food group was used. The numbers of factors to be retained for the description of food patterns were determined by components with eigenvalue $>1$ and examination of the scree plots. A four factor solution was identified. Items with factor loadings $\geq 0.4$ were used to calculate factor scores for each of the factors.

\section{Statistical analyses}

Factors were divided into tertiles and socio-demographic, anthropometric and dietary characteristics were examined by tertile.

Separate binary logistic regression analyses were performed for each factor to test whether the food pattern was associated with prostate cancer. In all multivariate models, adjustments were made for age, family history of prostate cancer in first degree relatives, education (as a measure of socioeconomic status) smoking, body mass index, alcohol and total energy intake. Analyses were performed using the Statistical Package for Social Sciences (SPSS) version 12. Statistical significance was achieved when $\mathrm{p}<0.05$.

\section{Results \\ Exclusions}

Thirty-six participants only partially completed, or did not complete the FFQ. Using a priori exclusion criteria of energy intakes less than 800 or greater than 5500 kilocalories, a further 36 subjects were excluded resulting in a total of 330 subjects for analyses of diet.

\section{Sample}

Men attending urology clinics $(n=972)$ enrolled in the study were screened by prostate specific antigen (PSA) and/or digital rectal examination (DRE). Seventy percent (681/972) of men screened had an abnormal PSA and/or DRE and 63\% (429/681) of these men were biopsied. Prostate cancer was diagnosed in $56.4 \%$ (242) of men biopsied. The characteristics of the 204 cases and their matched controls revealed that controls were on average 2 years younger than cases but had similar mean waist circumference and BMI. Reports of a family history of the disease were low in both groups and probably reflect significant underreporting.

\section{Food patterns}

Four food patterns emerged in our sample. Factor 1 showed a "healthy" pattern with high loadings for vegeta- 
bles, peas and beans and fruits. A "carbohydrate" pattern was seen in factor 2 (white bread and refined cereals, poultry, rice/pasta, starchy roots and tubers) whereas the third factor showed a "sugary foods and sweet baked products" pattern with high loadings for sugary foods, sweet baked goods and non-diet drink. Factor 4 showed an "organ meat and fast food" pattern and consisted of organ meat, fast food and salty snacks. Factor 1 was the dominant food pattern and explained $6.8 \%$ of the variance in intake and each of the remaining factors explained between $6.3 \%$ and $5.4 \%$ of the variance. Together, the 4 factors explained $24.5 \%$ of the variance.

There were few socio-demographic and health behaviour characteristics differences by dietary pattern tertiles. Men with high intakes of the carbohydrate pattern showed lower use of vitamins and were less likely to be overweight or obese than men in the lowest tertile. Men in the highest tertile of the sugary foods and sweet baked goods pattern were more likely to be current smokers and were less likely to have tertiary education. Men with high intakes of the organ meat and fast food pattern were more likely to be obese.

Odds ratios (CI) for the risk of prostate cancer according to tertiles of the food pattern scores are shown in Table 1. No association was found between any of the individual food patterns and risk of prostate cancer. As an individual's diet would comprise all food patterns we analysed the four food patterns adjusting for each other for their association with prostate cancer. In this analysis no association was found between the food patterns and risk of prostate cancer.

\section{Discussion}

The principal component analysis of our matched casecontrol study identified 4 food patterns: a "vegetables, peas, beans and fruits (healthy), a "carbohydrate" pattern, a "sugary foods and baked goods" pattern and an "organ meat and fast food" pattern. There were no significant associations between food patterns and risk of prostate cancer. Further examination of a model including all four food patterns also showed no evidence of an association with prostate cancer.

The absence of an association of dietary patterns with prostate cancer in our study is consistent with a recent prospective study of the U.S. health professionals that showed that neither the prudent or western dietary patterns were associated with the risk of prostate cancer [5]. In contrast, Tseng et al [6], suggested that higher intakes of a Southern pattern (cornbread, grits, sweet potatoes, okra, beans and rice) was protective, whereas Walker et al [7] reported that refined grain products, processed meats or red and organ meats increased the risk of prostate cancer. Higher intakes of healthy pattern in our study though suggestive, showed no evidence for an inverse association with risk of prostate cancer.

The absence of a relationship between dietary patterns and prostate cancer may be due to insufficient variability of dietary intakes or inaccurate measurement of the underlying pattern. Furthermore, associations may be obscured if undiagnosed prostate cancer cases were included as cancer-free men for comparisons.

Table I: Multivariate OR (CI) for Tertiles of 4 Food Patterns associated with Prostate Cancer in Jamaican men

\begin{tabular}{|c|c|c|c|}
\hline & \multicolumn{3}{|c|}{ Tertiles of dietary pattern score } \\
\hline & Tertile I (low) & Tertile 2 & Tertile 3 (high) \\
\hline \multicolumn{4}{|c|}{ Factor I: Vegtables, peas, beans \& fruits (Healthy) } \\
\hline Total prostate cancer cases & 111 & 108 & 110 \\
\hline Multivariate OR $(\mathrm{Cl})^{\mathrm{a}}$ & 1.00 (reference) & $0.72(0.39-1.32)$ & $0.84(0.44-1.59)$ \\
\hline \multicolumn{4}{|l|}{ Factor 2: Carbohydrate } \\
\hline Total prostate cancer cases & 110 & 109 & III \\
\hline Multivariate OR $(\mathrm{Cl})^{\mathrm{a}}$ & 1.00 (reference) & $1.28(0.70-2.34)$ & $1.20(0.58-2.48)$ \\
\hline \multicolumn{4}{|c|}{ Factor 3: Sugary foods \& sweet baked goods } \\
\hline Total prostate cancer cases & 102 & 113 & 115 \\
\hline Multivariate $\mathrm{OR}(\mathrm{Cl})^{\mathrm{a}}$ & 1.00 (reference) & $0.88(0.49-1.62)$ & $0.75(0.40-1.38)$ \\
\hline \multicolumn{4}{|l|}{ Factor 4: Organ meat and fast food } \\
\hline Total prostate cancer cases & 104 & 117 & 109 \\
\hline Multivariate $\mathrm{OR}(\mathrm{Cl})^{\mathrm{a}}$ & 1.00 (reference) & I.3I (0.73-2.33) & $0.96(0.53-1.76)$ \\
\hline \multicolumn{4}{|l|}{ Four dietary patterns:a } \\
\hline Vegetables, Peas \& Beans, fruits & 1.00 (reference) & $0.67(0.36-1.27)$ & $0.81(0.43-1.58)$ \\
\hline Carbohydrate & 1.00 (reference) & $1.27(0.69-2.36)$ & $1.16(0.55-2.47)$ \\
\hline Sugary foods \& sweet baked goods & 1.00 (reference) & $0.88(0.48-1.63)$ & $0.72(0.38-1.35)$ \\
\hline Organ meat and fast food & 1.00 (reference) & $1.26(0.70-2.27)$ & $0.88(0.47-1.63)$ \\
\hline
\end{tabular}

a All models adjusted for age, family history of prostate cancer, education, body mass index, smoking, alcohol and total energy intake. 


\section{Conclusion}

Our study suggested that the dietary patterns identified in our sample were not associated with risk of prostate cancer. Further investigations that better define cancer-free subjects and diet are needed to examine the contribution of diet to prostate cancer outcomes.

\section{Competing interests}

The authors declare that they have no competing interests.

\section{Authors' contributions}

All authors contributed to the design of the study. MJ, CS, $\mathrm{NM}$ and FB were responsible of the execution of the study. $\mathrm{MJ}$ conducted the analysis and drafted the manuscript. SW assisted with the analyses and contributed to the interpretation of results. All authors critically reviewed the manuscript.

\section{Acknowledgements}

This work was supported by the National Health Fund and the Planning Institute of Jamaica. The authors thank the staff and participants of the study for their important contributions.

This article has been published as part of Infectious Agents and Cancer. Volume 4 Supplement I, 2009: Second Annual International African-Caribbean Cancer Consortium Conference. The full contents of the supplement are available online at http://www.infectagentscancer.com/supplements/4/SI.

\section{References}

I. Blake G, Hanchard B, Mitchell K, Simpson D, Waugh N, Wolff C, Samuels E: Jamaica cancer mortality statistics, 1999. West Indian Med J 2002, 5 I (2):64-67.

2. Hanchard B, Blake G, Wolff C, Samuels E, Waugh N, Simpson D, Ramjit C, Mitchell K: Age-specific incidence of cancer in Kingston and St. Andrew, Jamaica, 1993 - 1997. West Indian Med J 200I, 50(2): I23-I29.

3. Kolonel LN: Nutrition and prostate cancer. Cancer Causes Control 1996, 7(1):83-44.

4. Kim J-O, Mueller C: Factor analysis: statistical methods and practical issues Newbury Park, CA: Sage publications, Inc; 1978.

5. Wu K, Hu FB, Willett WC, Giovannucci E: Dietary patterns and risk of prostate cancer in U.S. men. Cancer Epidemiol Biomarkers Prev 2006, 15(1):|67-I7|.

6. Tseng M, Breslow RA, DeVellis RF, Ziegler RG: Dietary patterns and prostate cancer risk in the National Health and Nutrition Examination Survey Epidemiological Follow-up Study cohort. Cancer Epidemiol Biomarkers Prev 2004, I 3(I):7I-77.

7. Walker M, Aronson KJ, King W, Wilson JW, Fan W, Heaton JP, MacNeily A, Nickel JC, Morales A: Dietary patterns and risk of prostate cancer in Ontario, Canada. Int J Cancer 2005, I l6(4):592-598.
Publish with Bio Med Central and every scientist can read your work free of charge

"BioMed Central will be the most significant development for disseminating the results of biomedical research in our lifetime. "

Sir Paul Nurse, Cancer Research UK

Your research papers will be:

- available free of charge to the entire biomedical community

- peer reviewed and published immediately upon acceptance

- cited in PubMed and archived on PubMed Central

- yours - you keep the copyright

Submit your manuscript here:

http://www.biomedcentral.com/info/publishing_adv.asp
BioMedcentral 